\title{
Molecular cloning and functional analysis of the thioredoxin gene SikTrxh from Saussurea involucrata
}

\author{
L. ZHANG ${ }^{1,+}$, C. $\mathrm{LIU}^{2,+}$, F.F. CHENG ${ }^{3,+}$, X.Y. GUO ${ }^{3}$, Y.X. $\mathrm{LI}^{3}$, A.Y. WANG ${ }^{3}$, and J.B. ZHU ${ }^{3, *}$ \\ ${ }^{1}$ Shihezi University of Medicine, Shihezi 832003, P.R. China \\ ${ }^{2}$ Agriculture College of Xinjiang Agriculture University, Urumqi, 830052, P.R. China \\ ${ }^{3}$ College of Life Science, Shihezi University, Shihezi 832003, P.R. China \\ *Corresponding author: E-mail: jianboz9@sina.com
}

\begin{abstract}
Thioredoxins are oxidoreductases that help to maintain redox homeostasis in plants under abiotic stress. In this study, a new thioredoxin gene, SikTrxh, was cloned from Saussurea involucrata (Kar. \& Kir.), a perennial herb that grows in the high alpine mountains of Central Asia. Bioinformatics analysis shows that the full-length cDNA of SikTrxh consisted of $565 \mathrm{bp}$ with a 354-bp open reading frame and encoded a 117 amino acid protein. Using quantitative reverse transcription (RT) PCR, we found that the expression of the SikTrxh gene was induced by salt, cold, and drought stresses, suggesting that this protein played a significant role in plant defense. Subcellular localization confirmed that the protein was localized to the mitochondria. A vector carrying SikTrxh was inserted into tobacco, and successfully modified plants were identified by RT-PCR. Physiological indicators and antioxidant enzyme activities were measured under low temperature, and salt and drought stresses. Our results show that malondialdehyde content and relative electrolyte leakage increased in both wild-type and SikTrxh-overexpressing transgenic plants; however, these increases were significantly higher in the wild-type plants than in the transgenic plants. We also found that photosystem II photoinhibition was lower in the transgenic plants than in the wild-type plants, and that activities of reactive oxygen species-scavenging enzymes were higher in the transgenic plants than in the wild-type plants. We conclude that SikTrxh can reduce toxic effects of reactive oxygen species to protect the plasma membrane, thereby increasing plant resistance to abiotic stresses.
\end{abstract}

Keywords: abiotic stresses, reactive oxygen species, thioredoxins, tobacco.

\section{Introduction}

Adverse environmental conditions, such as extreme temperatures, saline-alkaline conditions, and drought, can inhibit the growth, development, and productivity of plants. Plants have evolved versatile redox signaling and regulation mechanisms, some of which are controlled by thioredoxins (TRXs), to maintain redox homeostasis in harsh environmental conditions. TRX is a generic term for the large family of small, versatile, redox proteins found in all organisms (Meyer et al. 2005, 2009, Park et al. 2009, Rivas et al. 2004). Trxs are small (roughly $10-12 \mathrm{kDa}$ ) oxidoreductases that contain a highly conserved TrpCys-(Gly/Pro)-Pro-Cys (WC(G/P)PC) active site motif (Holmgren 1989). The redox activity of these proteins relies on the two Cys residues that, when reduced, induce

$\overline{\text { Received }} 13$ February 2020, last revision 21 October 2020, accepted 29 October 2020.

Abbreviations: APX - ascorbate peroxidase; CAT - catalase; cDNA - complementary DNA; $\mathrm{F}_{0}$ - minimal fluorescence; $\mathrm{F}_{\mathrm{m}}$ - maximal fluorescence; $\mathrm{F}_{\mathrm{v}}$ - variable fluorescence; $\mathrm{F}_{\mathrm{v}} / \mathrm{F}_{\mathrm{m}}$ - maximal photochemical efficiency of PS II; MDA - malondialdehyde; $\mathrm{O}_{2}{ }^{*-}$ - superoxide radical anion; MS - Murashige and Skoog; PEG - polyethylene glycol 6000; PS II - photosystem II; REL - relative electrolyte leakage; ROS - reactive oxygen species; RT-PCR - reverse transcription PCR; SOD - superoxide dismutase; Trxh - thioredoxin-h.

Acknowledgements: We would like to thank the Key Areas of Corps Science and Technology Reform Project (2020AB009), the National GMO Major Project (2016ZX080005004-009), the Key Scientific and Technological Projects for the Cultivation of New Varieties of Genetically Modified Organisms (2018ZX0800501B-005), and the National Natural Science Foundation of China (31360053) for their support. ${ }^{+}$These authors contributed equally.

Conflict of interest: The authors declare that they have no conflict of interest. 
reductive cleavage of a disulfide bond in target proteins via two nucleophilic substitution reactions (Serrato et al. 2003). These reactions allow Trxs to activate or deactivate the target protein and, consequently, the associated cellular redox pathway (Gromer et al. 2004). Trxs receive electrons from either one of two compartment-specific systems: the ferredoxin-TRX system, which reduces Trxs with electrons coming from ferredoxin through the action of ferredoxin-TRX reductase, or the NADPH-TRX system, in which NADPH-TRX reductase furnishes electrons from NADPH to Trxs (Gromer et al. 1998).

TRX proteins occur widely in plants, animals, and microorganisms. Large quantities of TRX have been identified in plants (Buchanan et al. 2005). Plant TRX proteins are divided into 6 types, according to their amino acid sequences and cellular distribution: $\mathrm{f}, \mathrm{m}, \mathrm{x}, \mathrm{y}, \mathrm{h}$, and $\mathrm{o}$ (Nuruzzaman et al. 2008). It is thought that members of different families regulate various redox-dependent cellular processes for a variety of proteins (Reichheld et al. 2002, Gelhaye et al. 2005, Hall et al. 2010, Meyer et al. 2012). The TRX type $\mathrm{h}$ proteins (TRXh) form the largest TRX family. TRXh has the most extensive cellular distribution, and different Trxh proteins have been located in subcellular structures such as cytoplasm (Montrichard et al. 2009), nucleus (Gelhaye et al. 2004), endoplasmic reticulum (Serrato et al. 2002), plasma membrane (Marcus et al. 1991), and mitochondria (Meng et al. 2010). They are the most structurally complex TRX proteins and have the greatest number of biochemical properties. The TRXh is considered to be the most versatile type in terms of redox pathways and other cellular processes involved in redox (Gelhaye et al. 2004, 2005). There are many Trxh proteins in plants, 11 Trxh genes have been identified in Arabidopsis thaliana (Meyer et al. 2005), and there are at least 10 Trxh genes in rice (Xie et al. 2009). However, only a few functions have been elucidated for the h-type Trxs, which represent the largest group of these proteins identified by sequencing (Park et al. 2009).

Trxh5 in A. thaliana is important in resisting virus and microbial infection (Sweat et al. 2007, Park et al. 2017). Trxh1 and Trxh4 in rice are involved separately in the fine regulation of the stress response to high salt (Zhang et al. 2011) and low phosphorus (Ying et al. 2017). Trxh5 in barley is involved in the regulation of grain germination (Wong et al. 2002). Further research showed that during seed germination, Trxh regulates disulfide bonds to increase the activity of starch hydrolase and increase the solubility of seed storage protein, thus promoting seed germination (Hägglund et al. 2013). Trxh is an electron donor that affects the activity of several oxidative stress response enzymes, including methionine sulfoxide reductase, peroxidase, and glutathione reductase (Rouhier et al. 2001, Fomenko et al. 2002). It is also thought to participate in other plant developmental pathways, including self-incompatibility (Cabrillac et al. 2001), carbon metabolism, and nitrogen metabolism (Baumann et al. 2002). The cited studies indicate that the Trxh gene is important in regulating plant growth and development as well as being involved in the stress response. In addition the development of proteomics tools has permitted the identification of potential targets of many TRXh proteins as reviewed in Montrichard et al. (2009).

In the present study, we investigated the expression of a new Trxh gene isolated from Saussurea involucrata (Kar. \& Kir.), referred to as SikTrxh. S. involucrata is a perennial herb that grows in the high mountains of central Asia, at altitudes of $2400-4100 \mathrm{~m}$, where the climate is often below freezing and snowy. S. involucrata has evolved unique physiological and biochemical mechanisms that allow it to survive under these conditions, making it a good subject for the study of abiotic stress tolerance in plants. Therefore, we introduced the SikTrxh gene into tobacco plants, and investigated the tolerance of the transformed tobacco plants to cold, drought, and salt. We also studied the expression of genes and activities of antioxidant enzymes that alleviate oxidative damage, including superoxide dismutase (SOD), ascorbate peroxidase (APX), and catalase (CAT), together with the accumulation of the reactive oxygen species (ROS) hydrogen peroxide $\left(\mathrm{H}_{2} \mathrm{O}_{2}\right)$ and superoxide radical anions $\left(\mathrm{O}_{2}{ }^{--}\right)$.

\section{Materials and methods}

Plants and growth conditions: Saussurea involucrata (Kar. \& Kir.) seedlings were cultured in Murashige and Skoog (MS) solid medium in a growth chamber with a 70 - $80 \%$ relative humidity, a 16 -h photoperiod, a photon flux density of $200 \mu \mathrm{mol} \mathrm{m} \mathrm{m}^{-2} \mathrm{~s}^{-1}$, and day/night temperatures of $21 / 19{ }^{\circ} \mathrm{C}$. Seeds of wild-type tobacco (Nicotiana tabacum L. cv. NC 89) and transgenic tobacco plant lines were germinated in MS medium for two weeks and then transplanted to containers filled with a 3:1 soil:sand mixture. The seedlings were grown for eight weeks either in a controlled environmental chamber or a greenhouse. The chamber was set to $25 / 20{ }^{\circ} \mathrm{C}$ day/night temperatures, a 16-h photoperiod, and a photon flux density of 500 $600 \mu \mathrm{mol} \mathrm{m} \mathrm{m}^{-2} \mathrm{~s}^{-1}$. The greenhouse was lit by natural light supplemented with high-pressure sodium lights; photon flux density was from $600 \mu \mathrm{mol} \mathrm{m} \mathrm{m}^{-2} \mathrm{~s}^{-1}$ at the pot level to $1600 \mu \mathrm{mol} \mathrm{m} \mathrm{m}^{-2} \mathrm{~s}^{-1}$ at the top of the plant. The positions of the plants were changed daily, and the plants were watered with a nutrient medium.

Cloning and sequence analysis of SikTrxh gene: Total RNA was isolated from leaves of $S$. involucrata using the TRIzol reagent (Takara Biotechnology, Shiga, Japan), and DNase I according to the manufacturer's instructions. A full-length cDNA library of $S$. involucrata was constructed using the Creator SMART cDNA library construction kit (Clontech, Mountain View, CA, USA) following the procedure described by Zhu et al. (2006). Ninety-six single clones were randomly selected and sequenced. One cDNA sequence showed homology to a gene encoding a thioredoxin-like protein. This cDNA sequence was named SikTrxh. The 5' end, the CDS region, and the 3' end of the SikTrxh gene were identified using open reading frame finder and aligned with known sequence databases. The obtained SikTrxh sequence was subjected to sequence alignment using DNAMAN (v. 8.0). Phylogenetic tree 
was reconstructed by MEGA 4.1 software (http://www. megasoftware.net/) using the Neighbor-Joining method and 1000 bootstrap replicates, bootstrap scores of $<50 \%$ were deleted.

Construction of SikTrxh gene expression vector in plants: SikTrxh cDNA was amplified using the forward primer 5'-GGATCCAAAATGGCGGAAGAAGGA-3' (the BamHI site is underlined) and the reverse primer 5'GAGCTCGGAAACACATAAGTTGCTG-3' (the SacI site is underlined) to construct the $\mathrm{pBI} 121-\mathrm{SikTrxh}$ recombinant plasmid. PCR products were digested with BamHI and SacI enzymes and ligated with the pBI121 vector, which contained the CaMV 35S promoter. After double digestion with the same enzymes, the $\beta$-glucuronidase (GUS) gene was replaced with the SikTrxh gene. The identity of the insert was confirmed by sequencing.

Subcellular localization of SikTrxh: The full-length open reading frame of SikTrxh without a stop codon was amplified by PCR with the primer SikTrxh-Sub, containing BamHI and XbaI restriction sites (Table 1 Suppl.). The fragment was then fused to the pCAMBIA2300-GFP expression vector to generate pCAMBIA2300- SikTrxhGFP, which is driven by the CaMV $35 \mathrm{~S}$ promoter. The p35S-SikTrxh-GFP plasmid and MT-rk mitochondria marker plasmid (Nelson et al. 2007) were transformed into Agrobacterium tumefaciens strain GV3101. These transformed constructs were infiltrated into tobacco abaxial leaf tissue using a syringe. The infiltrated leaves were incubated for $2 \mathrm{~d}$ in an irradiated cultivation chamber before being peeled. The subcellular localization of the GFP fusion protein was then imaged using a Leica SP8 confocal laser scanning microscope (Leica Microsystems, Heidelberg, Germany) with the excitation wavelengths set at 488,561 , and $633 \mathrm{~nm}$.

Plant transformation and transgenic tobacco identification: To create the transgenic tobacco plants, the pBI121-SikTrxh recombinant plasmid was introduced into A. tumefaciens strain GV3101 and then transformed into the tobacco using cotyledons as explants. Selected shoots were regenerated in MS medium containing $50 \mathrm{mg} \mathrm{dm}^{-3}$ kanamycin. When they had rooted, the kanamycin-resistant primary transformants (the $\mathrm{T}_{0}$ generation) were transferred to soil and allowed to growth till maturation. Kanamycinresistant plants were tested for the presence of the SikTrxh gene using PCR. The seeds from $\mathrm{T}_{0}$ plants were sown, and two fully independent transgenic $\mathrm{T}_{1}$ lines (OE-2 and OE-3) with comparatively high content of SikTrxh were used for further analysis.

Stress tolerance: Six-week-old seedlings of $\mathrm{T}_{2}$ wild-type and transgenic lines (OE-2 and OE-3) were randomly divided for cold stress tolerance tests. The seedlings were placed for $2 \mathrm{~h}$ in a cold chamber at $4,-1$, or $-2{ }^{\circ} \mathrm{C}$, control seedlings were kept at $25{ }^{\circ} \mathrm{C}$. Photographs of the seedlings were taken after they were exposed to the cold environment, the phenotypic changes in the whole plants were observed and analyzed. After a further $2 \mathrm{~d}$ of
$4{ }^{\circ} \mathrm{C}$ cold treatment, the second and third fully expanded leaves from the tops of all the plants were harvested for determining the activity of antioxidant enzymes and gene expressions (see below). After a disinfectant rinse, wildtype and transgenic seeds were separated and placed in a half MS medium. The seeds were stored at normal $\left(20^{\circ} \mathrm{C}\right)$ for $7 \mathrm{~d}$ or at low $\left(4^{\circ} \mathrm{C}\right)$ temperature for $14 \mathrm{~d}$. Survival rate was recorded.

The drought tolerance tests were carried out in a greenhouse maintained under natural irradiance at temperatures $22-25^{\circ} \mathrm{C}$. The six-week-old seedlings of both wild-type and transgenic $\mathrm{T}_{2}$ plants were watered, and each type of them were subsequently divided into two groups, i.e., a drought treatment group and a control group. Water was withheld from seedlings in the drought treatment for $12 \mathrm{~d}$. Seedlings in the control group were watered every $2 \mathrm{~d}$. After $12 \mathrm{~d}$, the first and second fully expanded leaves from the tops of all the plants were harvested to determine the activity of antioxidant enzymes and genes expressions. Photographs of the plants were taken after $0,3,6,9$, and $12 \mathrm{~d}$, the corresponding phenotypic changes were observed. After disinfection, seeds were separated and sown in the half MS mediums with different polyethylene glycol (PEG)-6000 concentrations $(0,5,10$, and $15 \%$, $\mathrm{m} / \mathrm{v}$ ). Survival rate was recorded.

Six-week-old wild-type and transgenic $\mathrm{T}_{2}$ plants were watered using a $150 \mathrm{mM} \mathrm{NaCl}$ solution for $12 \mathrm{~d}$ for the salinity tolerance tests. The control group was grown at $25{ }^{\circ} \mathrm{C}$ with non-saline water. After $12 \mathrm{~d}$, the first and second fully expanded leaves from the tops of all plants were harvested to determine the activity of antioxidant enzymes and gene expressions. Photographs of the plants were taken after $0,3,6,9$ and $12 \mathrm{~d}$, the phenotypic changes were observed. Disinfected seeds of both wild-type and transgenic plants were separated and seeded in the half MS medium containing a range of $\mathrm{NaCl}$ concentrations $(0$, 100,150 , and $200 \mathrm{mM}$ ). Survival rates were recorded.

All tests were repeated three times to produce representative results, and each sample was prepared in triplicate.

Physiological measurements: Malondialdehyde (MDA) content was determined by the modified thiobarbituric acid reaction using a spectrophotometer $(U V-160 \mathrm{~A}$, Shimadzu Scientific Instruments, Kyoto, Japan) as described by Du et al. (1992). Leaves excised from the tobacco plants were washed in deionized water, and leaf discs were punched out. Membrane damage was quantified by the MDA concentration.

Relative electrolyte leakage (REL) was determined using an EC215 conductivity meter (Markson Science, Del Mar, CA, USA), following the method described by Lutts and Kinet (1996). Relative conductance was calculated by the equation $\mathrm{REL}=(\mathrm{EC} 1-\mathrm{CW}) /(\mathrm{EC} 2-\mathrm{CW}) \times 100$, where $\mathrm{EC} 1$ is electrical conductivity during the first measurement, EC2 is electrical conductivity after boiling, and $\mathrm{CW}$ is conductivity of deionized water.

Maximal photochemical efficiency of PS II $\left(\mathrm{F}_{\mathrm{v}} / \mathrm{F}_{\mathrm{m}}\right)$ was measured from the tobacco leaves using a portable fluorescence analyzer (DUAL-PAM-100, Walz, Effeltrich, 
Germany). Leaves were dark-adapted for $30 \mathrm{~min}$ and then exposed to a saturating light pulse for $1 \mathrm{~s}$. The minimal fluorescence $\left(\mathrm{F}_{0}\right)$ in the dark-adapted state (fluorescence intensity when all PS II reaction centers are open) and the maximal fluorescence $\left(\mathrm{F}_{\mathrm{m}}\right)$ during the application of the saturating pulse (fluorescence intensity when all PS II reaction centers are closed) were measured. Variable fluorescence $\left(\mathrm{F}_{\mathrm{v}}=\mathrm{F}_{\mathrm{m}}-\mathrm{F}_{0}\right)$ was then calculated (Van Kooten et al. 1990).

Chlorophyll content was measured using the technique described by Zhao et al. (2016). Leaves were frozen in liquid nitrogen before being placed in ethanol and heated in a water bath. Total chlorophyll content was quantified at absorbance $\mathrm{A}_{654}$ on an Infinite M200 Pro microplate reader (Tecan Group, Männedorf, Switzerland) using the equation: chlorophyll content $=\mathrm{A}_{654} /(39.8 \times 200 \mathrm{mg}) \times$ 100 , where $\mathrm{A}_{654}$ is the absorbance reading and $200 \mathrm{mg}$ is the fresh mass of the initial leaf sample (Tetley et al. 1974). These experiments were repeated three times.

After the cold, drought, and salt treatments, samples of wild-type and transgenic $\mathrm{T}_{2}$ tobacco plant leaves were collected. The leaves were cut into pieces and homogenized in an ice bath with $4 \mathrm{~cm}^{3}$ of $50 \mathrm{mM}$ sodium phosphate buffer $(\mathrm{pH} 7.8)$ containing $1 \%(\mathrm{~m} / \mathrm{v})$ polyvinylpyrrolidone and $10 \mathrm{mM} \beta$-mercaptoethanol. The homogenate was transferred to a tube and centrifuged at $1509 \mathrm{~g}$ and $4{ }^{\circ} \mathrm{C}$ for $15 \mathrm{~min}$. The supernatant was then used to determine enzyme activity. We assessed the activity of superoxide dismutase (SOD) using the methods described by Beauchamp and Fridovich (1971), with the radiation absorption value read at $560 \mathrm{~nm}$. Ascorbate peroxidase (APX) activity was determined as the decrease in absorbance of ascorbate at $290 \mathrm{~nm}$, using the method described by Nakano and Asada (1981). The activity of catalase (CAT) was determined using the method of Cakmak and Marschner (1992). Absorbance was recorded by an Infinite M200 Pro microplate reader (Tecan Group).

Hydrogen peroxide and $\mathrm{O}_{2}{ }^{--}$content were determined from a standard curve, as described by Benikhlef et al. (2013). Absorption values were recorded at 415 and $530 \mathrm{~nm}$ using a spectrophotometer (UV-160A, Shimadzu Scientific Instruments, Kyoto, Japan).

Gene expression values: We evaluated the expression of SikTrxh gene in roots, stems, and leaves of $S$. involucrata growing under cold, drought, or salt stress. The $S$. involucrata seedlings with the same size and phenotype were selected for stress treatments after six weeks of growth. For the cold stress, the $S$. involucrata seedlings were treated at $4{ }^{\circ} \mathrm{C}$ for $24 \mathrm{~h}$. For the drought stress, the $S$. involucrata seedlings were then taken out of the medium and submerged in $20 \%$ (m/v) PEG 6000 for $24 \mathrm{~h}$. For the salt stress, the $S$. involucrata seedlings were taken out of the medium, and their roots were submerged in $200 \mathrm{mmol} \mathrm{NaCl}$ for $24 \mathrm{~h}$. Untreated plants were used as the controls. All plants were cultured in a $21^{\circ} \mathrm{C}$ (daily) and $19^{\circ} \mathrm{C}$ (overnight) cycle incubator in parallel. The leaves at the same position were harvested at $0,1,3,6,12$, and $24 \mathrm{~h}$ during the process of the cold, drought, or salt treatments to measure the expression patterns of SikTrxh gene.
The leaves of wild-type and transgenic $\mathrm{T}_{2}$ tobacco plants treated with the above mentined stress conditions were also used for the ROS-related stress-responsive genes superoxide dismutase $(N t S O D)$, ascorbate peroxidase (NtAPX), catalase $(N t C A T)$, late embryogenesis-abundant protein (NtLEA5), and $\Delta 1$-pyrroline-5- carboxylate synthetase $(N t P 5 C S)$. Regularly watered plants grown in a greenhouse at $25^{\circ} \mathrm{C}$ were used as control samples.

Three replicates were collected and stored in liquid nitrogen at $-80{ }^{\circ} \mathrm{C}$ for RNA isolation. Total RNA was extracted from the samples using TRIzol reagent (Takara Biotechnology), following the manufacturer's protocol. First-strand cDNA was synthesized using Oligo (dT) primer and PrimeScript RTase (Takara Biotechnology). Transcripts were then quantified by PCR analysis using SYBR Premix Ex Taq (Takara Biotechnology). Each RTPCR reaction was performed in $25 \mathrm{~mm}^{3}$ of final volume on iQ5 Multicolor real time PCR detection system (Bio-Rad, Hercules, USA). The sequences of primers used for gene expression analysis in this study are listed in Table 1 Suppl.

Statistical analysis: GraphPad Prism 7.0 and SigmaPlot 12 (SYSTAT software) were used for statistical analysis of the data. Relative expression of SikTrxh under abiotic stresses are reported as means \pm standard deviation of three replicate samples, leaves from three individual seedlings were considered as a replicate sample. Significant differences between the wild-type plants and each transgenic plant line were determined using Duncan's multiple range test.

\section{Results}

The full-length cDNA of SikTrxh consisted of $565 \mathrm{bp}$ with a 354-bp open reading frame that encodes a 117 amino acid protein. To better understand the features of SikTrxh, Fig. $1 A$ shows the sequence analysis of Trxh proteins isolated from $S$. involucrata and other plant species. It can be seen that SikTrxh contained the typical conserved dithiol/disulfide active site sequence WCGPC. A phylogenetic tree was constructed with rice and Arabidopsis h-type Trxs. The results showed that SikTrxh1, together with OsTRXh1, OsTRXh2, OsTRXh3, OsTRXh6, AtTRXh1, AtTRXh3, AtTRXh4 and AtTRXh5, belongs to the TRXh subgroup I (Fig. $1 B$ ).

We used GFP as a fusion protein marker to identify the localization of the protein. In epidermal cells of tobacco leaves transiently expressing SikTrxh-GFP, GFP signals were localized to the mitochondria (Fig. $2 A$ ). The mitochondrial localization of SikTrxh-GFP was confirmed by co-localization with the mitochondrial marker MT-rk (Fig. 2B-D).

To investigate SikTrxh expression in different organs of $S$. involucrata, we used real time quantitative RT-PCR to detect SikTrxh in the plant roots, stems, and leaves. SikTrxh was expressed in all the organs, but the highest expressions were recorded in the roots, followed by the leaves and the stems (Fig. 3A).

The relative expression of SikTrxh under different 


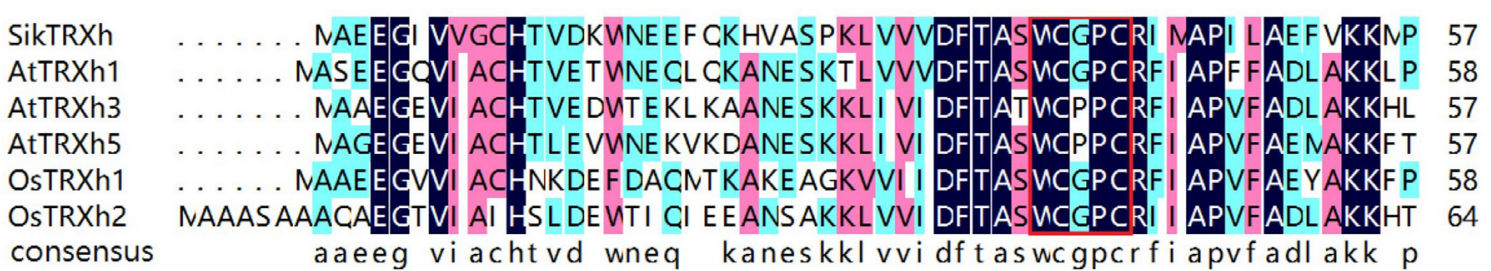

SikTRXh HVAFLKVDVDELESVAGEYSVEANPTFFFFKNGKEVDKVVGAKGE ELVSCI EKFSAVVAA. . . 117 AtTRXh1 NVLFL KVDTDELLKSVASDVAI OANPTF MFLLKEGKI L DKVVGAKKDEL CSTI AKHLA. . . . . . 114 AtTRXh3 DVVFF KVDVDEL NTVAEEF KVDANPTFI FNKEGEI KETVVGAAKEEI I ANLE KHKTVVAAA. . 118 AtTRXh5 NVVFFKI DVDEL CAVACEF KVEANPTIFVFMKEGNI I DRVVGAAKDEI NE KL NKHGGL VASA. . 118 OsTRXh1 GAVFLKVDVDELLKEVAEKYNVEANPTFLFI KDGAEADKVVGARKDDL CNTI VKHVGATAASAS 121 OSTRXh2 NAVFLKVDVDEL KPI AE CF SVEANPTFLFMKEGDVKDRVVGANKDEL ASKLELHNAN. . . . . 121 consensus nvvflkvdvdelk vaeef veamptf frkeg i dkvvga kdel s i ekh a vaa

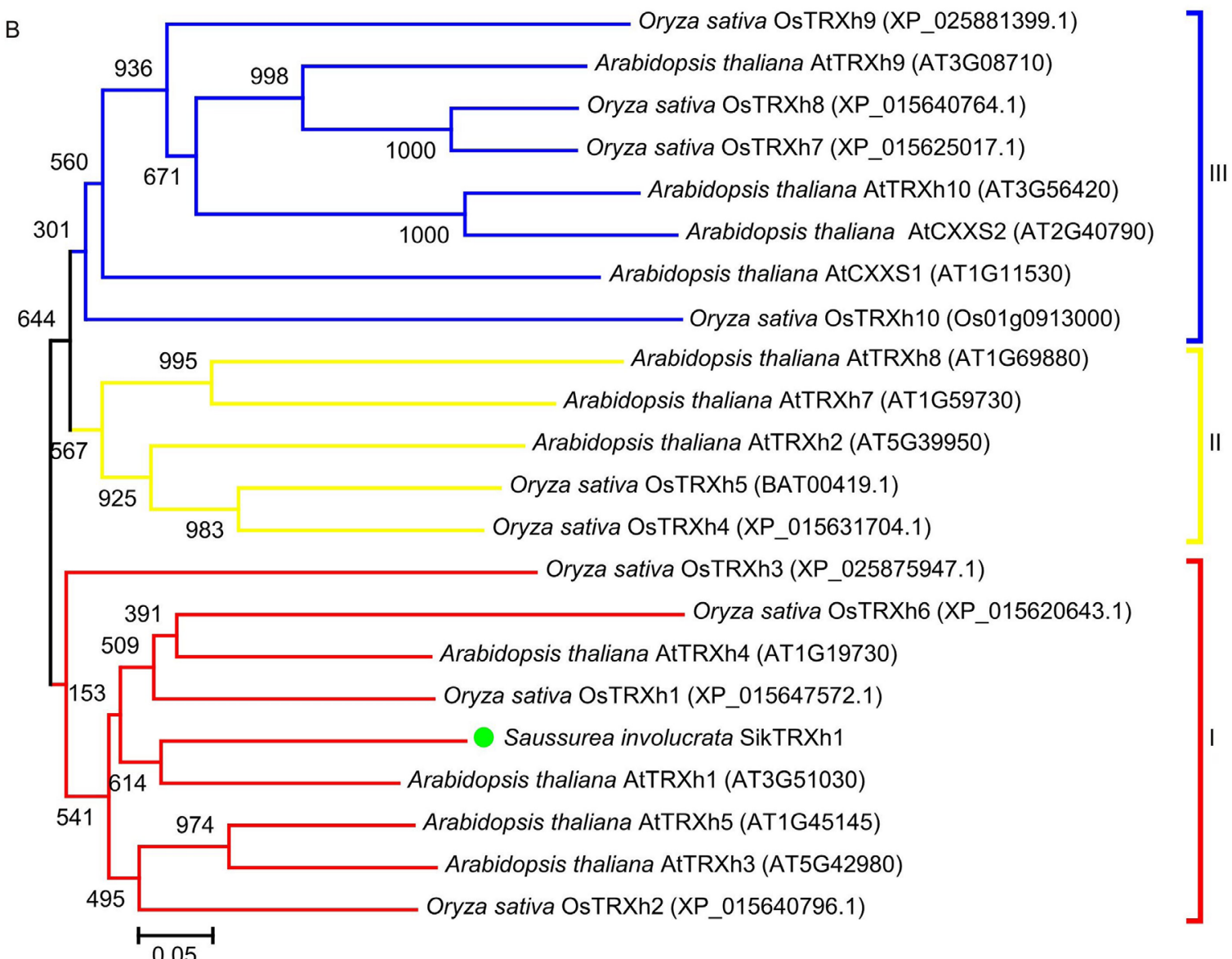

Fig. 1. Sequence analysis of Saussurea involucrata thioredoxin-h (SikTrxh). A - sequence comparison between the SikTrxh protein and homologous proteins from other species. $B$ - phylogenetic relationships of plant TRXh genes; Oryza sativa japonica: OsTRXh1 (XP 015647572.1), OsTRXh2 (XP 015640796.1), OsTRXh3 (XP 025875947.1), OsTRXh4 (XP 015631704.1), OsTRXh5 (BAT00419.1), OsTRXh6 (XP_015620643.1), OsTRXh7 (XP_015625017.1), OsTRXh8 (XP_015640764.1), OsTRXh9 (XP 025881399.1), and OsTRXh10 (Os0̄1g0913000). Arabidopsis thatiana: AtTRXh1 (AT3G51030), AtTRXh2 (AT5G39950), AtTRXh3 (AT5G42980), AtTRXh4 (AT1G19730), AtTRXh5 (AT1G45145), AtTRXh7 (AT1G59730), AtTRXh8 (AT1G69880), AtTRXh9 (AT3G08710), AtTRXh10 (AT3G56420), ATCXXS1 (AT1G11530), and ATCXXS2 (AT2G40790).

abiotic stresses was detected by quantitative RT-PCR. To test response to cold temperature, expression of SikTrxh transcripts in $S$. involucrata was initially induced with exposure to cold, a temperature of $4^{\circ} \mathrm{C}$ (Fig. $3 B$ ). The gene reached its highest expression at $1 \mathrm{~h}$. Expression decreased slightly after that, then gradually decreased to levels close to the control expression at $24 \mathrm{~h}$. To test for exposure to drought, expression of SikTrxh was induced 

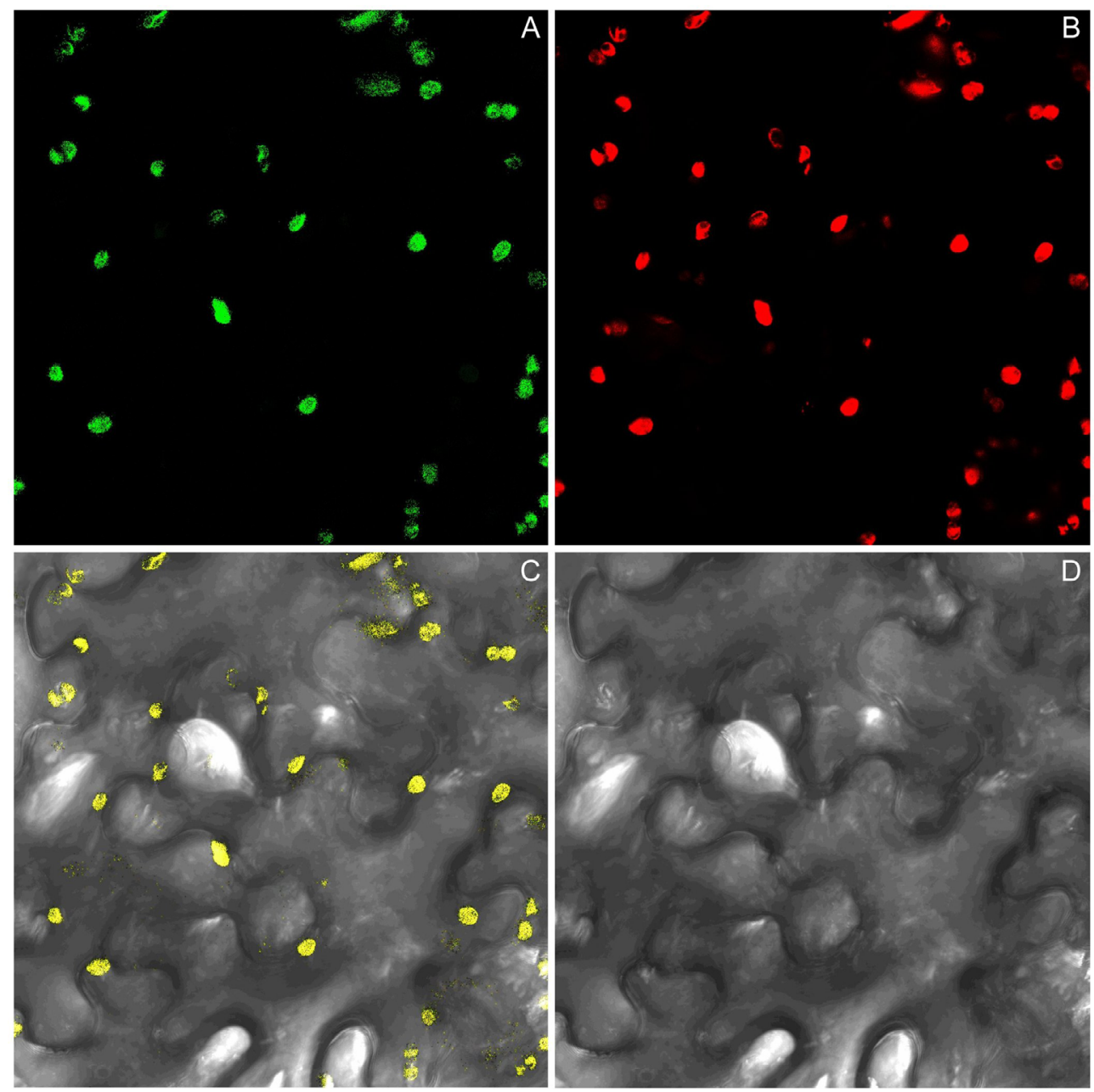

Fig. 2. Subcellular localization of Saussurea involucrata thioredoxin-h (SikTrxh). Confocal images of tobacco leaf epidermal cells transiently expressing SikTrxh-green fluorescent protein (GFP) and a mitochondria marker (MT-rk). $A$ - fluorescence image of tobacco leaf epidermal cells expressing the SikTrxh-GFP fusion protein. $B$ - fluorescence image of mitochondria in tobacco leaf epidermal cells with MT-rk. $C$ - merged fluorescence image of tobacco leaf epidermal cells expressing the SikTrxh-GFP fusion protein and MT-rk marker. $D$ - image of tobacco leaf epidermal cells under bright light. $A, B$ - dark field and $C, D$ - bright field.

when $S$. involucrata was exposed to $10 \%(\mathrm{~m} / \mathrm{v})$ PEG6000, reaching peak expression after $3 \mathrm{~h}$ (Fig. 3C). Expression gradually decreased, although expressions at $6 \mathrm{~h}$ were still three times higher than of the pre-treatment control. After $12 \mathrm{~h}$, expression was one third that of the control, and after $24 \mathrm{~h}$, only one fifth that of the control. In the test of exposure to salt, after $1 \mathrm{~h}$ in $150 \mathrm{mM} \mathrm{NaCl}$, SikTrxh expression increased rapidly, reaching expression nearly five times that of the control (Fig. 3D). Expression then gradually decreased, after $3 \mathrm{~h}$, expression was just less than four times that of the control, after $6 \mathrm{~h}, 2.5$ times that of the control, and after $12 \mathrm{~h}$, less than two times that of the control. After $24 \mathrm{~h}$, expression slightly increased to over three times that of the control. These results indicate that SikTrxh expression was induced by low temperature, drought, and salt stress. We hypothesize that this gene regulates stress responses in $S$. involucrata.

We generated five independent kanamycin-resistant primary transgenic tobacco plants $\left(\mathrm{T}_{0}\right.$ generation). PCR analysis confirmed that the SikTrxh gene was successfully introduced into the plants. Three of the transgenic tobacco plants were confirmed by PCR amplification using a CaMV35S forward and gene-specific reverse primer pair. We selected two independent transgenic tobacco lines for further study (OE-2 and OE-3). Semiquantitative RTPCR and quantitative RT-PCR showed that both tobacco lines showed SikTrxh expression, and SikTrxh expression was slightly higher in the OE-2 line than in the OE-3 line (Fig. 1 Suppl.).

Both the wild-type and the transgenic plants performed well under normal conditions, and there were no significant differences in their growth (Fig. 2 Suppl.). After the $4{ }^{\circ} \mathrm{C}$ treatment, wilting was observed in wild-type plants, but the growth of the overexpressing SikTrxh plants was not affected, they had sturdy and erect stems with green ovatelanceolate leaves. At $-1^{\circ} \mathrm{C}$, the stems of the wild-type plants became flaccid and the leaves displayed obvious wilting, whereas the stem and leaves of the two transgenic plants sagged slightly. When subjected to $-2{ }^{\circ} \mathrm{C}$ for $2 \mathrm{~h}$, the leaves of the wild-type plants became severely wilted, and the 


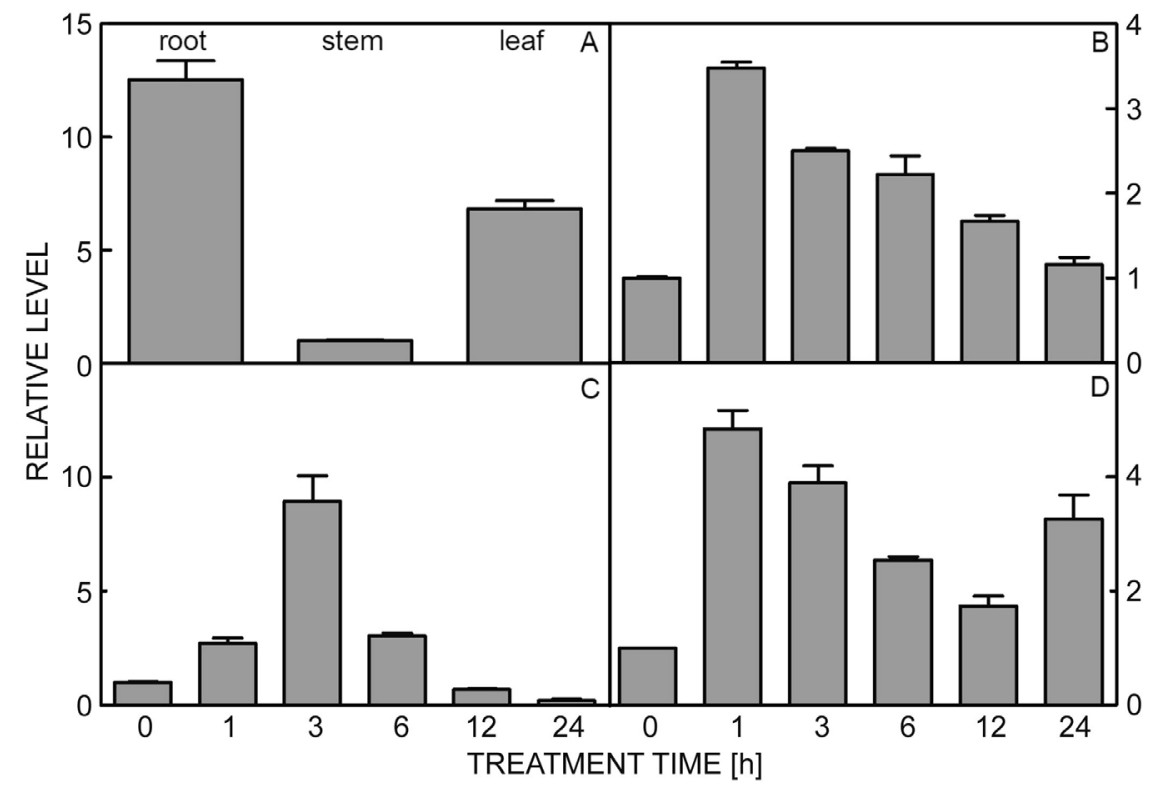

Fig. 3. Expression pattern analyses of Saussurea involucrata thioredoxin- $h$ (SikTrxh). A - tissue-specific expressions of SikTrxh in leaf, root, and stem of 6-week-old S. involucrata. B - expression of SikTrxh in S. involucrata under low temperature treatment $\left(4{ }^{\circ} \mathrm{C}\right)$ for 0 , 1, 3, 6, 12, and 24 h. $C$ - expression of SikTrxh in S. involucrata under drought treatment caused by $10 \%$ (m/v) PEG 6000 for $0,1,3,6$, 12, and 24 h. $D$ - expression of SikTrxh in S. involucrata under $150 \mathrm{mM} \mathrm{NaCl}$ treatment for $0,1,3,6,12$, and $24 \mathrm{~h}$.

plants were no longer viable. In contrast, the leaves of the OE-2 line showed moderate wilting and those of the OE-3 line showed slight wilting. All transgenic plants remained viable after the cold treatment. We tested the survival rates of the plants by seedling analysis. The tobacco seedlings showed no differences under normal conditions, but after 8 -h exposure to $-2{ }^{\circ} \mathrm{C}$, all seedlings wilted. They quickly recovered after $2-\mathrm{d}$ exposure to $25^{\circ} \mathrm{C}$. The survival rate of the control group was $20 \%$, but the survival rates of the transgenic strains were 60 and $40 \%$ (Fig. 2 Suppl.).

The transgenic lines showed increased resistance to drought stress. The transgenic plants began to wilt after $9 \mathrm{~d}$ of drought stress, while the wild-type plants began to wilt after $6 \mathrm{~d}$. After $9 \mathrm{~d}$ of drought treatment, the wild-type plants were thoroughly wilted (Fig. 3 Suppl.). Similarly, after $12 \mathrm{~d}$ of drought treatment, the control seedlings turned yellow. After a $2 \mathrm{~d}$ recovery period, the control group survival rate was $27.5 \%$, and the survival rates of the two transgenic strains were 55 and $45 \%$ (Fig. 3 Suppl.). These results suggest that SikTrxh is important in increasing drought tolerance in tobacco plants.

Salt stress causes water shortages in tissues. This results in cellular osmotic stress and the accumulation of reactive oxygen species. A $150 \mathrm{mM} \mathrm{NaCl}$ solution was used to test the salt tolerance of six-week-old wild-type and transgenic $\mathrm{T}_{2}$ plants. After $6 \mathrm{~d}$ of treatment with the $\mathrm{NaCl}$ solution, the leaves of the wild-type tobacco plants yellowed but the leaves of the transgenic plants did not change color. After $9 \mathrm{~d}$, the leaves of the wild-type plants were severely dehydrated and the leaves of transgenic plants began to turn yellow. Most of the leaves of both types of plant, had thickened. After $12 \mathrm{~d}$, most of the wild-type plants was withered and the leaves of the transgenic strains were yellowed (Fig. 4 Suppl.). When two-week-old wild-type and transgenic plants were treated with salt stress for $12 \mathrm{~d}$, the transgenic plants were in a better conditions than the wild-type plants. The survival rates of the transgenic plants were 60 and $46 \%$ and the survival rate of the wildtype plants was $22 \%$ (Fig. 4 Suppl.).

We found that malondialdehyde (MDA) content increased and relative electrolyte leakage (REL) became elevated when the wild-type and transgenic plants were exposed to cold, drought, and salt stresses (Fig. 4A-B). Both MDA and REL were considerably higher in the wild-type plants than in the transgenic lines. The differences were significant $(P<0.01)$. Proline accumulation also increased in all plants after stress but more in the transgenic plants than in the wild-type plants (Fig. 4C). Proline content in the wild-type plants was significantly lower than in the transgenic plants $(P<0.01)$. The $\mathrm{OE}-2$ line consistently had the highest proline content. Before the stress treatments, the maximum photochemical efficiency of photosystem II $\left(\mathrm{F}_{\mathrm{v}} / \mathrm{F}_{\mathrm{m}}\right)$ was almost equal for wild-type and transgenic plants (Fig. 4D). The $\mathrm{F}_{\mathrm{v}} / \mathrm{F}_{\mathrm{m}}$ decreased continuously in all plants under salt, cold, and drought stresses. However, the decrease was more pronounced in the wild-type plants, and the differences between wild-type and transgenic plants were significant $(P<0.01)$. Chlorophyll content was significantly higher in the transgenic plants than in the wild-type plants (Fig. 4E).

Superoxide dismutase (SOD), ascorbate peroxidase (APX), and catalase (CAT) activities were measured to investigate effects of SikTrxh expression on reactive oxygen species scavenging under salt, cold, heat, and drought stresses. The reactive oxygen species hydrogen peroxide $\left(\mathrm{H}_{2} \mathrm{O}_{2}\right)$ and the superoxide anion $\left(\mathrm{O}_{2}{ }^{-}\right)$were also measured. We found that SOD, APX, and CAT activities varied in response to salt, cold, and drought stresses 


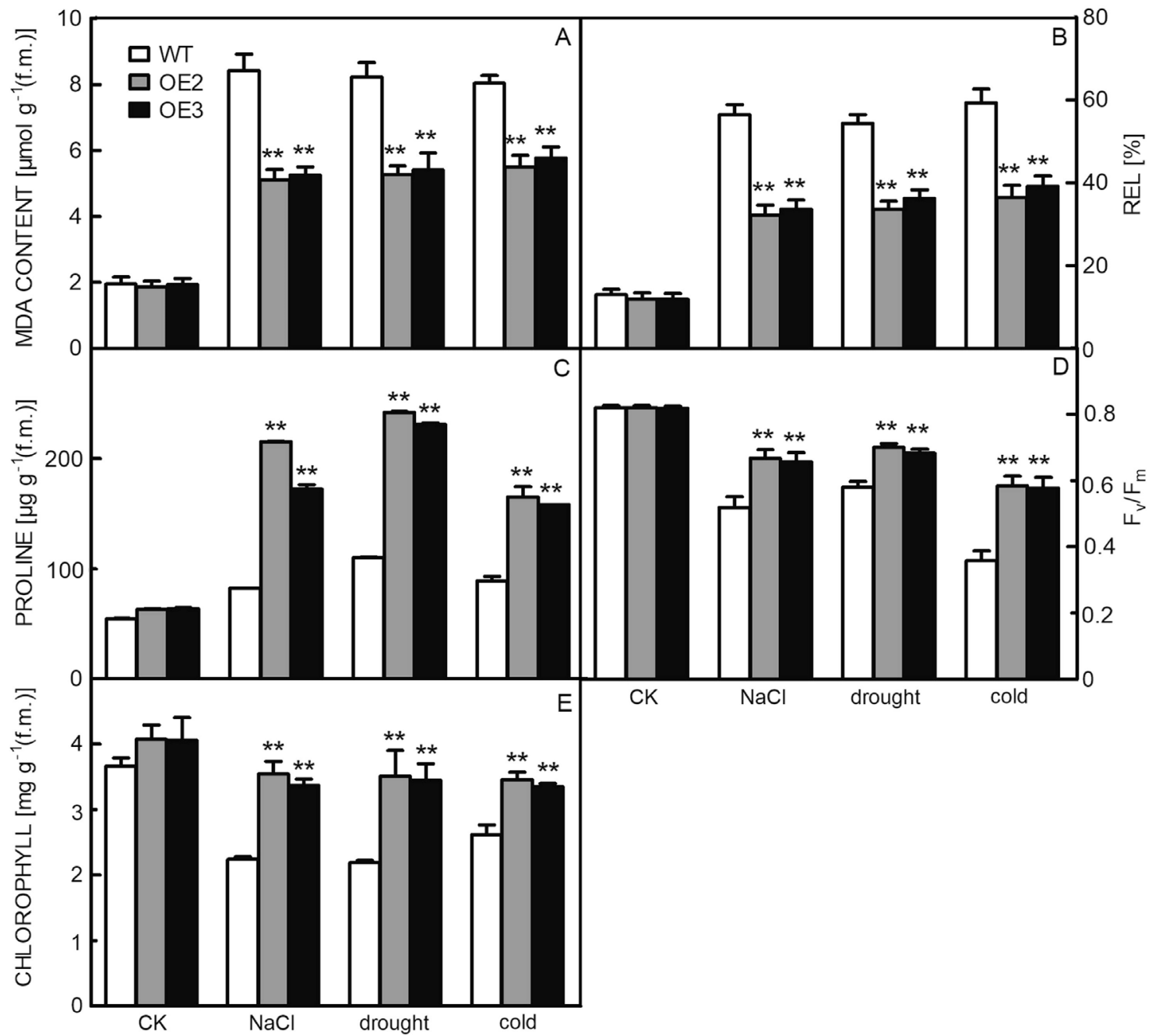

Fig. 4. Physiological analysis of wild-type and transgenic Saussurea involucrata thioredoxin-h tobacco plants after salt $(\mathrm{NaCl})$, drought, and cold stresses. Malondialdehyde (MDA) content $(A)$, relative electrolyte leakage (REL) $(B)$, proline content $(C)$, maximal photochemical efficiency of photosystem II $\left(\mathrm{F}_{\mathrm{v}} / \mathrm{F}_{\mathrm{m}}\right)(D)$, and chlorophyll content $(E)$. CK $-25{ }^{\circ} \mathrm{C}$ under normal conditions. Data for the wild-type plants are means \pm SEs of three replicates, and data for the transgenic plants are means \pm SEs of three different lines; $* *$ -significant differences $(P<0.01)$.

(Fig. 5A-C). Transgenic lines routinely showed higher enzyme activities than the wild-type plants. The differences between wild-type and transgenic plants in each treatment were significant. The SikTrxh-overexpressing line OE-2 regularly showed the highest enzyme activity.

Before the salt, cold, and drought stress tests, $\mathrm{H}_{2} \mathrm{O}_{2}$ and $\mathrm{O}_{2}{ }^{-}$content was low and almost identical between the wild-type and transgenic plants (Fig. 5D-E). Following exposure to salt, cold, and drought stresses, ROS content increased, considerably more in the wild-type plants than in the transgenic plants. Differences between wild-type and transgenic plants were significant for both the cold and drought stresses.

Gene expression patterns of the tobacco genes for stress response (NtSOD, NtAPX, and NtCAT) and membrane protection (NtLEA5 and NtP5CS) were determined for wild-type and transgenic plants. Transgenic lines showed significantly higher gene expressions than wild-type plants for each treatment (Fig. 6).

\section{Discussion}

Abiotic stresses such as salt, drought, and cold caused persistent damage and seriously affected crop growth and yield. Major abiotic stresses can be expected to damage more than $50 \%$ of a crop. The impact on a crop may be even more severe due to instability caused by environmental degradation (Mittler et al. 2006). Plants are more susceptible to environmental factors than animals because they are fixed in the soil and lack mobility. Plants have evolved complex mechanisms to improve their tolerance to abiotic and biotic stresses (Nakashima et al. 2006). Plants growing in extreme environments have been naturally selected to form stable genetically controlled structures and functions that result in physiological and biochemical mechanisms that adapt the plants to these conditions. S. involucrata, a medicinal plant found in Xinjiang, is one such plant. S. involucrata is a typical alpine perennial plant that has strong antioxidant and free 


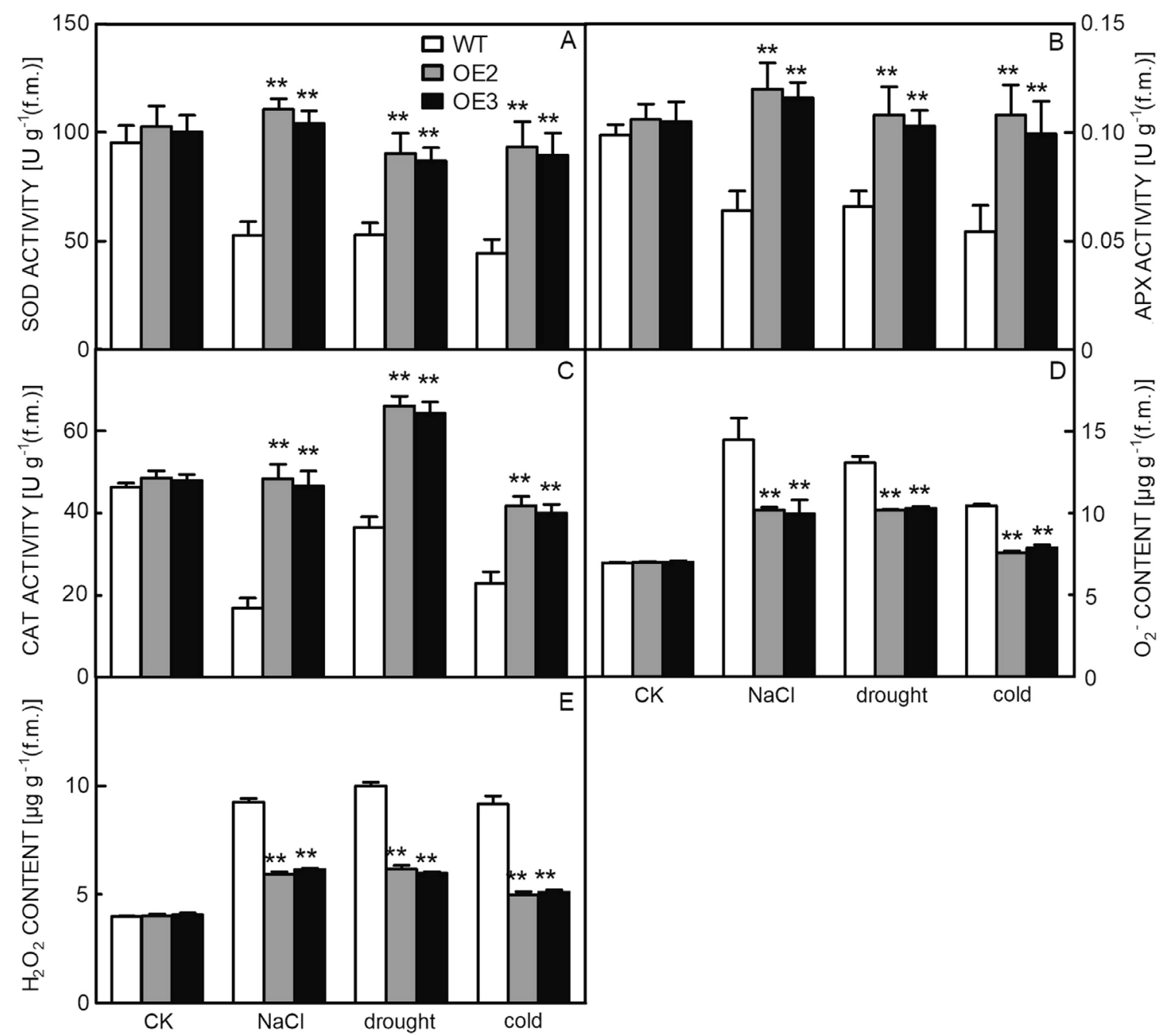

Fig. 5. Antioxidant enzyme activities and accumulation of reactive oxygen species in wild-type and transgenic Saussurea involucrata thioredoxin- $h$ plant lines (OE-2 and $\mathrm{OE}-3)$ under salt $(\mathrm{NaCl})$, drought, and cold stresses. SOD superoxide dismutase, APX - ascorbate peroxidase, CAT - catalase, $\mathrm{O}_{2}^{--}$- superoxide radical anions. CK - $25^{\circ} \mathrm{C}$ under normal conditions. Data for the wild-type and transgenic plants are means \pm SEs of three replicates; ${ }^{* *}$ - significant differences between wild-type and transgenic plants at $P<0.01$.

radical scavenging abilities that adapt it to the extreme environment.

In this study, a new thioredoxin gene SikTrxh was cloned using the full-length cDNA library RT-PCR. Analysis of the SikTrxh amino acid sequence shows that the gene belongs to the first subgroup of the plant thioredoxin gene family, $T R X h$, and it is located in the mitochondria. Plant mitochondria are the main sites of ROS production (Venditti et al. 2014). Abiotic stressors, such as drought, cold, and salt, increase ROS production and so lead to ROS-related damage (Giraud et al. 2008).

Verification of gene expression by quantitative RTPCR provided basic information on probable gene functions. Many new genes have been identified by functional analysis or gene expression analysis from organisms subjected to different stresses (Bruzzone et al. 2008, Jozefczuk and Adjaye 2011). Studies have shown that Trxh is expressed in response to abiotic stress. For example, the expression profile of plant thioredoxin varies in different tissues (Reichheld et al. 2002). The thioredoxin gene $S c T R X h 1$ was isolated from sugar cane and classified into the 1 subgroup of thioredoxin genes. Studies have also shown that the relative abundance of ScTRXh1 expressed in sugar cane roots, stems, and buds was higher by a factor of 12 - 33 than in the leaves (Guo et al. 2012). However, the SikTrxh used in this study had different expression characteristics. The SikTrxh was principally expressed in the roots, followed by the leaves, and little in the stems. This result suggests that SikTrxh has different biological functions in S. involucrata. Zhang et al. (2008) cloned the thioredoxin gene LbTRXm2 of Limonium bicolor and found that the gene was inhibited when the plant was subjected to low temperature, salt $(\mathrm{NaCl})$, or PEG stress. Wang et al. (2011) showed that after salt stress, GmTRXh1 expression in salt-tolerant soybean cultivars is significantly higher than in salt-sensitive cultivars. Yan et al. (2006) showed that the expression of thioredoxin in rice is induced by low temperature stress. Serrato et al. (2003) showed that under oxidative stress, thioredoxin is enriched in the nucleus of wheat seeds. However, we found that SikTrxh showed 


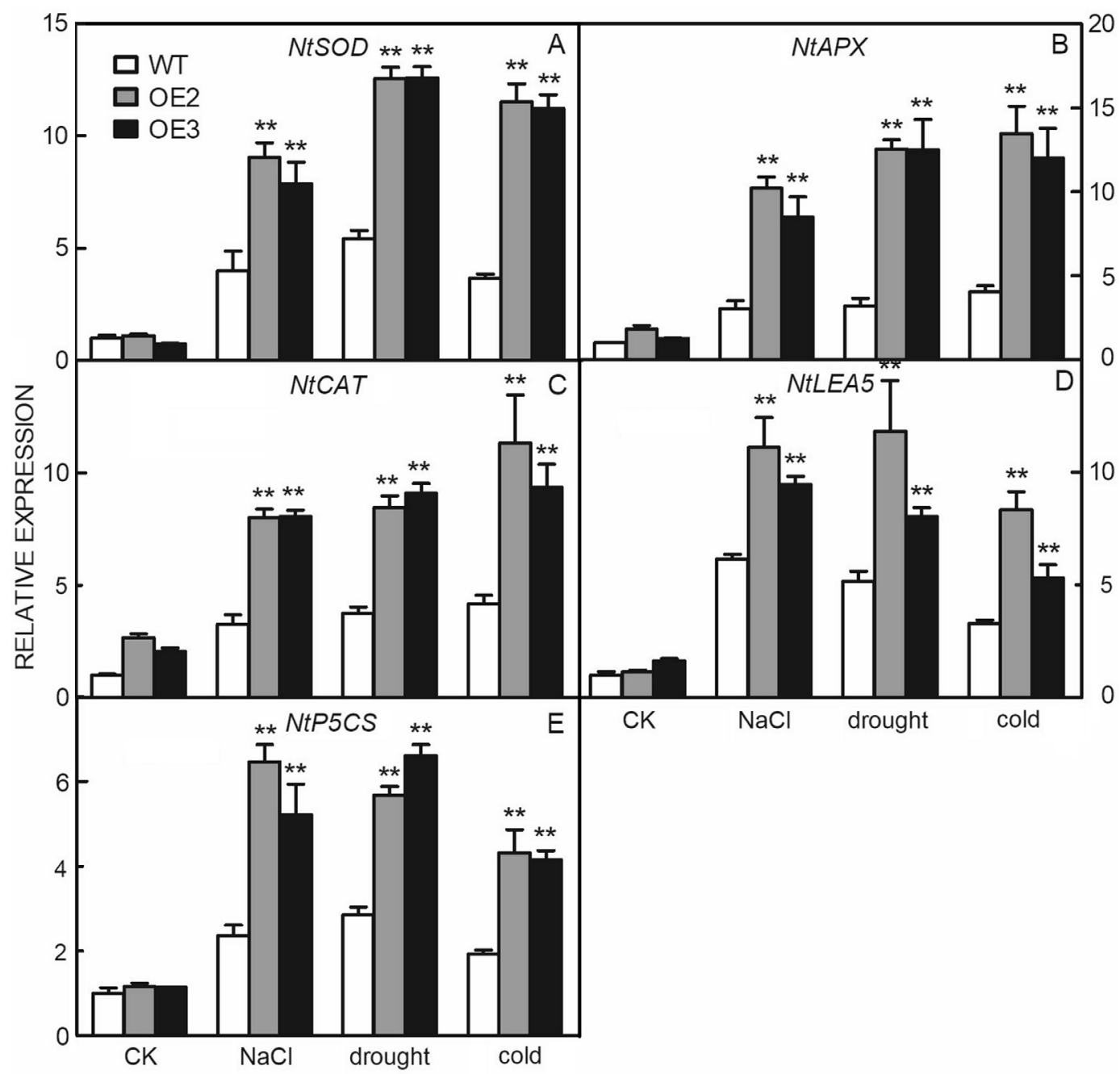

Fig. 6. Relative expressions of Nicotiana tabacum superoxide dismutase (NtSOD) (A), Nicotiana tabacum ascorbate peroxidase (NtAPX) $(B)$, Nicotiana tabacum catalase (NtCAT) (C), Nicotiana tabacum late embryogenesis-abundant protein (NtLEA5) (D), and Nicotiana tabacum $\triangle 1$-pyrroline-5- carboxylate synthetase (NtP5CS) (E) in wild-type and transgenic Saussurea involucrata thioredoxin- $h$ plants (lines $\mathrm{OE}-2$ and $\mathrm{OE}-3$ ) under salt $(\mathrm{NaCl})$, drought, and cold stresses. $\mathrm{CK}-25{ }^{\circ} \mathrm{C}$ under normal conditions. Data are means $\pm \mathrm{SEs}$ of three replicates; ** - significant differences between wild-type and transgenic plants at $P<0.01$.

significant up-regulated and down-regulated changes. Some characteristics of thioredoxin gene expression in $S$. involucrata suggest that $T R X$ gene functionality differs depending on its source. The results of our study not only enriched the study on thioredoxin gene of $S$. involucrata, but also form the foundation of a deeper investigation into the function of SikTrxh and its activity in resistance to abiotic stress.

The phenomenon of abiotic stress causing excessive production of reactive oxygen species in plants and leading to oxidative damage of biological macromolecules has been confirmed in soybean, pea, barley, wheat, Arabidopsis thaliana and other plants (Holmgren et al. 1989, Meyer et al. 2005, Delisle et al. 2001, Yamamoto et al. 2001, Darkó et al. 2004, Tamás et al. 2004). When a plant is under stress, its defense system enzymes will be activated to resist any damage caused by the stress (Gelhaye et al. 2004). Trxh is an important redox agent. The expression of Trxh genes is often associated with an increase in oxygen anions.
Plant antioxidant responses can be involved in a variety of pathways. Li et al. (2010) found TRX gene overexpression in barley together with decreased $\mathrm{H}_{2} \mathrm{O}_{2}$ and MDA content. Hence, the study shows that $T R X$ genes can effectively relieve $\mathrm{H}_{2} \mathrm{O}_{2}$ oxidation damage of barley seedling leaves. Also the ability of seedlings to resist aluminum stress was enhanced, and the tolerance to high temperature, drought, and strong irradiance at the later stage of grain filling was improved. Prabu et al. (2011) showed that the expression of the sugarcane $S c N A C 23$ transcription factor gene highly interacted with the thioredoxin $h 1$ gene, which may be due to regulation by the formation of disulfide bonds between ScNAC23 cysteine residues and sugarcane thioredoxin, when induced by low temperature $\left(4^{\circ} \mathrm{C}\right)$ and drought stress. Zhang et al. (2011) found that OSTRXh1, which can be secreted into the ectoplasmic body, was involved in the regulation of the ectoplasmic reactive oxygen species, and thus affected the growth, development, and stress response of rice. These studies provide important theoretical basis 
for the importance of $T R X$ genes in plant resistance.

The transgenic SikTrxh tobacco strains were more resistant to low temperature, drought, and high salinity than the wild-type plants. SikTrxh gene overexpression reduces the damage caused by various plant stressors, SikTrxh activates the anti-stress signaling pathway of tobacco, thereby increasing stress resistance in the transgenic plants.

Many studies have shown that abiotic stress leads to ROS accumulation, mainly in the form of $\mathrm{H}_{2} \mathrm{O}_{2}$ and $\mathrm{O}_{2}{ }^{--}$. These important signal transduction molecules increase intracellular free $\mathrm{Ca}^{2+}$ and act as secondary signal messengers (Misra et al. 2009). However, excessive amounts of $\mathrm{H}_{2} \mathrm{O}_{2}$ and $\mathrm{O}_{2}{ }^{-}$during stress can lead to malondialdehyde accumulation and membrane damage. Membrane damage and lipid peroxidation have been used to indicate plant tolerance to abiotic stress (Wang et al. 2012). We used change in MDA content and relative membrane conductivity to analyze membrane lipid peroxidation and membrane damage under different stresses. Our results showed that different stresses caused severe membrane lipid peroxidation and cell membrane damage in tobacco, which was consistent with the results of previous studies. Transgenic tobacco was significantly less susceptible to membrane lipid peroxidation and membrane damage than wild-type tobacco (the control group). Free proline is also important in plant self-protection and cellular proline content is directly related to stress resistance (Sleator et al. 2001). Our results showed that under different stress treatments, proline content in the leaves of transgenic tobacco plants was significantly higher than in wild-type plants, thus confirming the stress resistance of transgenic tobacco plants.

Membrane damage and elevated content of ROS can lead to chlorophyll degradation (Stepien et al. 2009). We found that chlorophyll content was higher in transgenic SikTrxh-overexpressed tobacco than in wild-type plants, likely due to high antioxidant enzyme activities in the transgenic plants. SOD, CAT, and APX activities were significantly higher in the transgenic plants than in the wild-type plants. These three enzymes are important components of the antioxidant enzyme system: CAT directly catalyzes hydrogen peroxide $\left(\mathrm{H}_{2} \mathrm{O}_{2}\right)$ to produce water and oxygen, APX takes ascorbic acid as the substrate to decompose $\mathrm{H}_{2} \mathrm{O}_{2}$, and SOD is a key enzyme in the ROS scavenging system that rapidly transforms $\mathrm{O}_{2}^{-{ }^{--}}$into $\mathrm{O}_{2}$ or $\mathrm{H}_{2} \mathrm{O}_{2}$. The increased activity of these antioxidant enzymes removes reactive oxygen species produced by stress and thus protects macromolecules from oxidative damage.

Corresponding to enzyme activity, the expression of encoding genes (NtSOD, NtCAT, and NtAPX) were significantly higher in transgenic strains OE-2 and OE-3 than in the wild-type plants. It is generally thought that the redox state of proteins is controlled by the oxidationreducing agents of cells, Trx is an important oxidationreducing agent. Some enzymes belonging to antioxidants contain conserved cysteine residues. Catalase, glutathione peroxidase, peroxidase, SOD $(\mathrm{Cu}-\mathrm{Zn}), \mathrm{APX}$, and 2-cys peroxiredoxins contain $5,1,8,2,2$, and 1 conserved cysteine residues, respectively, which may be targets of
Trxh (Wong et al. 2004). It is possible that the reduced Trxh can transfer electrons to these enzymes, thus providing a reduction equivalent for the regulation of enzyme activity, or it may be that Trxh is involved in the regulation of signal cascades dependent on the redox state; this area needs further investigation.

\section{Conclusions}

The SikTrxh gene was isolated from the S. involucrata. Overexpression of the SikTrxh gene increased the survival rate of transgenic tobacco plants subjected to low temperature, drought, or salt. The transgenic tobacco plants showed increased activity of CAT, SOD, APX and other antioxidant enzymes which could remove ROS produced in response to low temperature, drought, and salt stress more effectively than in the wild type plants. The enhanced enzyme activities also reduced oxidative damage to membrane lipids and proteins, thus increasing the resistance of transgenic tobacco plants to low temperature, drought, and salt stresses. To better counter abiotic stresses, it is necessary to breed new stress-resistant plant cultivars. Our experiments with transgenic tobacco plants showed that a $T R X h$ gene can increase plant resistance to low temperature, drought, and high salt stresses by increasing antioxidant enzyme activities and therefore provide a theoretical foundation for the cultivation of resistant crop cultivars.

\section{References}

Baumann, U., Juttner, J.: Plant thioredoxins: the multiplicity conundrum. - Cell. mol Life Sci. 59: 1042-1057, 2002.

Beauchamp, C., Fridovich, I.: Superoxide dismutase: improved assays and an assay applicable to acrylamide gels. - Anal. Biochem. 44: 276-287, 1971.

Benikhlef, L., L'Haridon, F., Abou-Mansour, E., Serrano, M., Binda, M., Costa, A., Lehmann, S., Métraux, J.P.: Perception of soft mechanical stress in Arabidopsis leaves activates disease resistance. - BMC Plant Biol. 13: 1-12, 2013.

Bruzzone, C.M., Belcher, J.D., Schuld, N.J., Newman, K.A., Vineyard, J., Nguyen, J., Chen, C., Beckman, J.D., Steer, C.J., Vercellotti, G.M.: Quantitative real-time polymerase chain reaction (qRT-PCR) restriction fragment length polymorphism (RFLP) method for monitoring highly conserved transgene expression during gene therapy. - Translational Res. 152: 290297, 2008.

Buchanan, B.B., Balmer, Y.: Redox regulation: A broadening horizon. - Annu. Rev. Plant Biol. 56: 187-220, 2005.

Cabrillac, D., Cock, J.M., Dumas, C., Gaude, T.: The S-locus receptor kinase is inhibited by thioredoxins and activated by pollen coat proteins. - Nature 410: 220-223, 2001.

Cakmak, I., Marschner, H.: Magnesium deficiency and high light intensity enhance activities of superoxide dismutase, ascorbate peroxidase, and glutathione reductase in bean leaves. - Plant Physiol. 98: 1222-1227, 1992.

Delisle, G., Champoux, M., Houde, M.: Characterization of oxalate oxidase and cell death in Al-sensitive and tolerant wheat roots. - Plant Cell Physiol. 42: 324-333, 2001.

Du, Z., Bramlage, W.J.: Modified thiobarbituric acid assay for measuring lipid oxidation in sugar-rich plant tissue extracts. - 
J. Agr. Food Chem. 40: 1566-1570, 1992.

Darkó, É., Ambrus, H., Stefanovits-Bányai, É., Fodor, J., Bakos, F., Barnabás, B.: Aluminium toxicity, Al tolerance and oxidative stress in an Al-sensitive wheat genotype and in Altolerant lines developed by in vitro microspore selection. Plant Sci. 166: 583-591, 2004.

Fomenko, D.E., Gladyshev, V.N.: CxxS: fold-independent redox motif revealed by genome-wide searches for thiol/disulfide oxidoreductase function. - Protein Sci. 11: 2285-2296, 2002.

Gelhaye, E., Rouhier, N., Gerard, J., Jolivet, Y., Gualberto, J., Navrot, N., Ohlsson, P.I., Wingsle, G., Hirasawa, M., Knaff, D.B., Wang, H., Dizengremel, P., Meyer, Y., Jacquot, J.P.: A specific form of thioredoxin $\mathrm{h}$ occurs in plant mitochondria and regulates the alternative oxidase. - Proc. nat. Acad. Sci. USA 101: 14545-14550, 2004.

Gelhaye, E., Rouhier, N., Jacquot, J.P.: The thioredoxin $h$ system of higher plants. - Plant Physiol. Biochem. 42: 265-271, 2004.

Gelhaye, E., Rouhier, N., Navrot, N., Jacquot, J.P.: The plant thioredoxin system. - Cell. mol. Life Sci. 62: 24-35, 2005.

Giraud, E., Ho, L.H.M., Clifton, R., Carroll, A., Estavillo, G., Tan, Y.F., Howell, K.A., Ivanova, A., Pogson, B.J., Millar, A.H., Whelan, J.: The absence of alternative oxidase 1a in Arabidopsis results in acute sensitivity to combined light and drought stress. - Plant Physiol. 147: 595-610, 2008.

Gromer, S., Urig, S., Becker, K.: The thioredoxin system-from science to clinic. - Med. Res. Rev. 24: 40-89, 2004.

Gromer, S., Wissing, J., Behne, D., Ashman, K., Schirmer, R.H., Flohé, L., Becker, K.: A hypothesis on the catalytic mechanism of the selenoenzyme thioredoxin reductase. Biochem J. 332: 591-592, 1998

Guo, J.L., Zheng, R., Ling, H., Fu, H.Y., Su, Y.C., Wang, H.B.: Cloning and expression analysis of a thioredoxin gene ScTRXh1 from sugarcane (Saccharum complex). - Genomics appl. Biol. 6: 574-581, 2012.

Hall, M., Mata-Cabana, A., Akerlund, H.E., Florencio, F.J., Schröder, W.P., Lindahl, M., Kieselbach, T.: Thioredoxin targets of the plant chloroplast lumen and their implications for plastid function. - Proteomics 10: 987-1001, 2010.

Hägglund, P., Björnberg, O., Navrot, N., Jensen, J.M., Maeda, K., Kirkensgaard, K., Shahpiri, A., Sultan, A., Bunkenborg, J., Gubler, F., Barrero, J.M., Henriksen, A., Finnie, C., Svensson, B.: The barley grain thioredoxin system - an update. - Front. Plant Sci. 4: 151, 2013.

Holmgren, A.: Thioredoxin and glutaredoxin systems. - J. Biol. Chem. 264: 13963-13966, 1989.

Jozefczuk, J., Adjaye, J.: Quantitative real-time PCR-based analysis of gene expression. - Methods Enzymol. 500: 99109, 2011.

Li, Q.Y., Niu, H.B., Ma, Y., Ren, J.P., Li, Y.C., Yin, J.: Effects of overexpressing Trxs on antioxidant enzymes activities in transgenic barley seedling leaves under ultraviolet B stress. J. Henan agr. Univ. 4: 365-369, 2010.

Lutts, S., Kinet, J.M., Bouharmont, J.: NaCl-induced senescence in leaves of rice (Oryza sativa L.) cultivars differing in salinity resistance. - Ann. Bot. 78: 389-398, 1996.

Marcus, F., Chamberlain, S.H., Chu, C., Masiarz, F.R., Shin, S., Yee, B.C., Buchanan, B.B.: Plant thioredoxin h: an animallike thioredoxin occurring in multiple cell compartments. Arch. Biochem. Biophys. 287: 195-198, 1991.

Meng, L., Wong, J.H., Feldman, L.J., Lemaux, P.G., Buchanan, B.B.: A membrane-associated thioredoxin required for plant growth moves from cell to cell, suggestive of a role in intercellular communication. - Proc. nat. Acad. Sci. USA 107: 3900-3905, 2010.

Meyer, Y., Belin, C., Delorme-Hinoux, V., Reichheld, J.P., Riondet, C.: Thioredoxin and glutaredoxin systems in plants: molecular mechanisms, crosstalks, and functional significance. - Antioxid. Redox Signal. 17: 1124-1160, 2012.

Meyer, Y., Buchanan, B.B., Vignols, F., Reichheld, J.P.: Thioredoxins and glutaredoxins: unifying elements in redox biology. - Annu. Rev. Genet. 43: 335-367, 2009.

Meyer, Y., Reichheld, J.P., Vignols, F.: Thioredoxins in Arabidopsis and other plants. - Photosynth. Res. 86: 419-433, 2005.

Misra, M.K., Sarwat, M., Bhakuni, P., Tuteja, R., Tuteja, N.: Oxidative stress and ischemic myocardial syndromes. - Med. Sci. Monitor: internat. med. J. exp. clin. Res. 15: 209-219, 2009.

Mittler, R., Kim, Y., Song, L., Coutu, J., Coutu, A., CiftciYilmaz, S., Lee, H., Stevenson, B., Zhu, J.K.: Gain- and lossof-function mutations in Zat10 enhance the tolerance of plants to abiotic stress. - FEBS Lett. 11: 6537-6542, 2006.

Montrichard, F., Alkhalfioui, F., Yano, H., Vensel, W.H., Hurkman, W.J., Buchanan, B.B.: Thioredoxin targets in plants: the first 30 years. - J. Proteomics 72: 452-474, 2009.

Nakano, Y., Asada, K.: Hydrogen peroxide is scavenged by ascorbate-specific peroxidase in spinach chloroplast. - Plant Cell Physiol. 22: 867-880, 1981.

Nakashima, K., Fujita, Y., Katsura, K., Maruyama, K., Narusaka, Y., Seki, M., Shinozaki, K., Shinozaki, K.Y.: Transcriptional regulation of $\mathrm{ABI} 3$ - and $\mathrm{ABA}-$ responsive genes including $R D 29 B$ and $R D 29 A$ in seeds, germinating embryos, and seedlings of Arabidopsis. - Plant mol. Biol. 60: 51-68, 2006.

Nelson, B.K., Cai, X., Nebenführ, A.: A multicolored set of in vivo organelle markers for co-localization studies in Arabidopsis and other plants. - Plant J. 51: 1126-1136, 2007.

Nuruzzaman, M., Gupta, M., Zhang, C., Wang, L., Xie, W., Xiong, L., Zhang, Q., Lian, X.: Sequence and expression analysis of the thioredoxin protein gene family in rice. - Mol. Genet. Genomics 280: 139-151, 2008.

Park, S.C., Jung, Y.J., Kim, I.R., Lee, Y., Kim, Y.M., Jang, M.K., Lee, J.R.: Functional characterization of thioredoxin h type 5 with antimicrobial activity from Arabidopsis thaliana. Biotechnol. Bioprocess Eng. 22: 129-135, 2017.

Park, S.K., Jung, Y.J., Lee, J.R., Lee, Y.M., Jang, H.H., Lee, S.S., Park, J.H., Kim, S.Y., Moon, J.C., Lee, S.Y., Chae, H.B., Shin, M.R., Jung, J.H., Kim, M.G., Kim, W.Y., Yun, D.J., Lee, K.O., Lee, S.Y.: Heat-shock and redox-dependent functional switching of an h-type Arabidopsis thioredoxin from a disulfide reductase to a molecular chaperone. - Plant Physiol. 150: 552-561, 2009.

Prabu, G., Kawar, P.G., Pagariya, M.C., Prasad, D.T.: Identification of water deficit stress upregulated genes in sugarcane. - Plant mol. Biol. Rep. 29: 291-304, 2011.

Reichheld, J.P., Mestres-Ortega, D., Laloi, C., Meyer, Y.: The multigenic family of thioredixin $\mathrm{h}$ in Arabidopsis thaliana: specific expression and stress response. - Plant Physiol. Biochem. 40: 685-690, 2002.

Rivas, S., Rougon-Cardoso, A., Smoker, M., Schauser, L., Yoshioka, H., Jones, J.D.: CITRX thioredoxin interacts with the tomato Cf-9 resistance protein and negatively regulates defence. - Eur. mol. Biol. Organ. J. 23: 2156-2165, 2004.

Rouhier, N., Gelhaye, E., Sautiere, P.E., Brun, A., Laurent, P., Tagu, D., Gerard, J., De Fa, E., Meyer, Y., Jacquot, J.P.: Isolation and characterization of a new peroxiredoxin from poplar sieve tubes that uses either glutaredoxin or thioredoxin as a proton donor. - Plant Physiol. 127: 1299-1309, 2001.

Serrato, A.J., Cejudo, F.J.: Type-h thioredoxins accumulate in the nucleus of developing wheat seed tissues suffering oxidative stress. - Planta 217: 392-399, 2003.

Serrato, A.J., Pérez-Ruiz, J.M., Cejudo, F.J.: Cloning of thioredoxin $h$ reductase and characterization of the thioredoxin 
reductase-thioredoxin h system from wheat. - Biochem. J. 367: 491-497, 2002

Sleator, R.D., Gahan, C.G., Hill, C.: Identification and disruption of the proBA locus in Listeria monocytogenes: role of proline biosynthesis in salt tolerance and murine infection. - Appl. environ. Microbiol. 67: 2571-2577, 2001.

Stepien, P., Johnson, G.N.: Contrasting responses of photosynthesis to salt stress in the glycophyte Arabidopsis and the halophyte Thellungiella: role of the plastid terminal oxidase as an alternative electron sink. - Plant Physiol. 149: 1154-1165, 2009.

Sweat, T.A., Wolpert, T.J.: Thioredoxin h5 is required for victor insensitivity mediated by a CC-NBS-LRR gene in Arabidopsis. - Plant Cell 19: 673-687, 2007.

Tamás, L., Šimonovičová, M., Huttová, J., Mistrík, I.: Aluminium stimulated hydrogen peroxide production of germinating barley seeds. - Environ. exp. Bot. 51: 281-288, 2004.

Tetley, R.M., Thimann, K.V.: The metabolism of oat leaves during senescence: I. respiration, carbohydrate metabolism, and the action of cytokinins. - Plant Physiol. 54: 294-303, 1974.

Van Kooten, O., Snel, J.F.H.: The use of chlorophyll fluorescence nomenclature in plant stress physiology. - Photosynth. Res. 25: 147-150, 1990.

Venditti, P., Napolitano, G., Di Meo, S.: Role of enzymatic and non-enzymatic processes in $\mathrm{H}_{2} \mathrm{O}_{2}$ removal by rat liver and heart mitochondria. - J. Bioenerg. Biomembr. 46: 83-91, 2014.

Wang, S., Liang, D., Li, C., Hao, Y., Ma, F., Shu, H.: Influence of drought stress on the cellular ultrastructure and antioxidant system in leaves of drought-tolerant and drought-sensitive apple rootstocks. - Plant Physiol. Biochem. 51: 81-89, 2012.

Wang, W.Q., Hou W.S.: Clone and analysis of thioredoxin gene from soybean (Glycine max L.). - Soybean Sci. 3: 351-355, 2011.

Wong, J.H., Cai, N., Balmer, Y., Tanaka, C.K., Vensel, W.H., Hurkman, W.J., Buchanan, B.B.: Thioredoxin targets of developing wheat seeds identified by complementary proteomic approaches. - Phytochemistry 65: 1629-1640, 2004.
Wong, J.H., Kim, Y.B., Ren, P.H., Cai, N., Cho, M.J., Hedden, P., Lemaux, P.G., Buchanan, B.B.: Transgenic barley grain overexpressing thioredoxin shows evidence that the starchy endosperm communicates with the embryo and the aleurone. - Proc. nat Acad. Sci, USA 99: 16325-16330, 2002.

Xie, G., Kato, H., Sasaki, K., Imai, R.: A cold-induced thioredoxin $\mathrm{h}$ of rice, ostrx 23 , negatively regulates kinase activities of osmpk3 and osmpk6 in vitro. - FEBS Lett. 583: 2734-2738, 2009.

Yamamoto, Y., Kobayashi, Y., Matsumoto, H.: Lipid peroxidation is an early symptom triggered by aluminum, but not the primary cause of elongation inhibition in pea roots. - Plant Physiol. 125: 199-208, 2001.

Yan, S.P., Zhang, Q.Y., Tang, Z.C., Su, W.A., Sun, W.N.: Comparative proteomic analysis provides new insights into chilling stress responses in rice. - Mol. Cell. Proteomics 5: 484-496, 2006.

Ying, Y., Yue, W., Wang, S., Li, S., Wang, M., Zhao, Y., Wang, C., Mao, C., Whelan, J., Shou, H.: Two h-type thioredoxins interact with the E2 ubiquitin conjugase $\mathrm{PHO}_{2}$ to fine-tune phosphate homeostasis in rice. - Plant Physiol. 173: 812, 2017.

Zhang, C.J., Zhao, B.C., Ge, W.N., Zhang, Y.F., Song, Y., Sun, D.Y., Guo, Y.: An apoplastic h-type thioredoxin is involved in the stress response through regulation of the apoplastic reactive oxygen species in rice. - Plant Physiol. 157: 18841899, 2011

Zhang, D.W., Yang, C.P., Wang, Y.C., Ban, Q.Y., Ma, H.: Cloning and expression analysis of thioredoxin gene $(\operatorname{Tr} x)$ from Limonium bicolor. - Plant Physiol. Commun. 44: 201-205, 2008.

Zhao, F., Ma, J., Li, L., Fan, S., Guo, Y., Song, M., Wei, H., Pang, C., Yu, S.: GhNAC12, a neutral candidate gene, leads to early aging in cotton (Gossypium hirsutum L). - Gene 576: 268274, 2016.

Zhu, J.B., Liu, H.L., Wang, Z., Zhou, P.: Construction of fulllength cDNA library from the Saussurea involucrate Kar. et Kir laminae. - Acta agr. boreali-occident. sin. 6: 170-173, 2006. 